\title{
INSTITUTIONAL \\ ENCOURAGEMENT OF AND FACULTY ENGAGEMENT IN THE \\ SCHOLARSHIP OF TEACHING AND LEARNING
}

Thomas F. Nelson Laird, Tony Ribera, Indiana University

Framed by Huber and Hutchings's defining features of the scholarship of teaching and learning (SoTL), the study described in this chapter examines institutional encouragement of and faculty engagement in SoTL. Faculty at forty-nine U.S. colleges and universities participating in the 2009 Faculty Survey of Student Engagement completed items about SoTL. Results suggest that institutional encouragement of and faculty engagement in the public dissemination of teaching investigations lag behind encouragement and engagement in other aspects of SoTL. Some faculty subgroups (among them, women and faculty in education) on average feel more institutional encouragement and engage in SoTL activities more than their colleagues do.

Faculty who engage in the scholarship of teaching and learning (SoTL) approach the classroom as a research site, assessing student learning and evaluating teaching methods in order to promote student learning and advance the profession (Huber \& Hutchings, 2005). Essentially SoTL "is about the combining of research and teaching/learning into one activity" (Dobbins, 2008, p. 1). Pecorino and Kincaid (2007) and Shulman (2000) argue that as professional educators, all faculty have an obligation to engage in SoTL. In doing so, they not only improve their own quality of instruction but also further the teaching profession (Pecorino \& Kincaid, 2007). Despite calls for faculty to engage in such work, little is known about the level of faculty engagement in SoTL. 
Although engagement in SoTL seems to be on the rise, there has been no large, multicampus assessment of the extent of faculty engagement in SoTL or what faculty characteristics (gender, race, discipline, and rank) predict this type of engagement. There is also little empirical evidence about faculty perceptions of institutional support for SoTL. We use data from the 2009 Faculty Survey of Student Engagement (FSSE) to address these research questions.

\section{SoTL Defined}

As evidenced by pedagogical journals in sociology and chemistry (McKinney, 2007), scholarly work on teaching and learning has been present in certain disciplines for many years. More recently, scholars have explored scholarly work on teaching and learning in broader terms. Cross (1986) encouraged college instructors to become classroom researchers, exploring their teaching and student learning. Chism, Sanders, and Zitlow (1987) encouraged faculty to continually examine and reflect on their teaching practices by gathering feedback and discussing pedagogy with colleagues. In his significant text, Scholarship Reconsidered: Priorities of the Professoriate, Boyer (1990) built on these ideas. Addressing an imbalance in faculty work, Boyer encouraged professors to expand the definition of scholarship to include a scholarly approach to teaching, and by so doing to garner for SoTL the recognition and resources that had typically been reserved for traditional research (Pace \& Erekson, 2006). Despite drawing much attention, Boyer's (1990) conceptualization of SoTL was met with resistance and critique (Bender, 2005). Most notably, Boyer failed to present a clear distinction between scholarly teaching and SoTL (Hutchings \& Shulman, 1999; McKinney, 2004). Since Boyer, agreement has been building that scholarly teachers stay informed on current trends and issues in the field and use theory and research to inform their efforts. Such faculty members reflect on their teaching practices and assess student learning to improve their teaching (Kiener, 2009; McKinney, 2004; Shulman, 2000). However, scholarly teaching is not synonymous with SoTL, which goes beyond individual development (Boshier, 2009; Kiener, 2009). Huber and Hutchings (2005) describe four defining features of SoTL: (1) questioning, (2) gathering and exploring evidence, (3) trying out and refining new insights, and (4) going public. Thus, SoTL consists of peer-reviewed scholarship that is publicly disseminated in order to advance the scholarly efforts of others who are investigating teaching and learning (Cambridge, 2000; Cottrell \& Jones, 2003; Huber, 2001; Hutchings \& Shulman, 1999; Shulman, 1999). 
Surveying eighty-five faculty from a large, public research university in the Northwest, Myers (2008) found that the average faculty member "sometimes" did SoTL activities like reviewing literature on teaching and learning issues and using assessment findings to inform changes to courses. Myers also found that female faculty tend to engage in SoTL more than male faculty do and that the gender gap increases with years of teaching experience. Whitman and Richlin (2007) explored SoTL across disciplines. They found that SoTL is most prevalent in the natural sciences and professions and that it is slowly becoming valued in the humanities. Although these studies provide a glimpse of faculty engagement in SoTL, more work is needed.

\section{Methods}

The Faculty Survey of Student Engagement measures faculty perceptions and expectations of undergraduate student engagement in educationally purposeful activities as well as the extent to which faculty promote student learning and development in their courses and interactions with students (Kuh, Nelson Laird, \& Umbach, 2004). Faculty members at forty-nine colleges and universities across the United States were invited to complete a set of items concerning SoTL that were added to the end of the FSSE questionnaire. The participating colleges and universities that included the extra items represent a wide cross-section of U.S. baccalaureate-granting institutions. Based on the 2005 revision of the Carnegie Classification (http://classifications.carnegiefoundation.org), 24 percent of the institutions were doctoral or research universities, 39 percent were master's universities, 6 percent were baccalaureate colleges-arts and sciences, 18 percent were baccalaureate colleges-diverse, and 12 percent were other types such as schools of business and management and baccalaureate/ associate's colleges). Slightly over half of the institutions were private ( 53 percent). Undergraduate enrollments ranged from just over two hundred students to slightly over twenty thousand, with a mean of fifty-eight hundred. Response rates ranged from 17 to 89 percent, with an average response rate of 49 percent.

After deleting cases for missing data, the sample for this study consisted of 4,229 faculty members. About 45 percent of the respondents were female. Three-fourths ( 76 percent) were white, with 5 percent African American, 1 percent American Indian, 5 percent Asian, 3 percent Hispanic, 1 percent other, 1 percent multiracial, and 8 percent indicated a preference not to identify race/ethnicity. Most of the respondents were U.S. citizens (92 percent). Nearly seven of ten had a doctorate (69 percent). The age of 
the respondents ranged from twenty-one to eighty-two, with a mean of fifty. Various ranks and employment statuses were represented, with 13 percent of the respondents being part-time instructors or lecturers, 11 percent fulltime instructors or lecturers, 28 percent assistant professors, 25 percent associate professors, and 23 percent full professors. The number of courses taught by faculty during the academic year ranged from one to eighteen, with 44 percent of respondents reporting a class load between four and six. Slightly over a third of the faculty taught at least one graduate-level course.

Respondents taught in a wide range of fields. A relatively large percentage were in the arts and humanities (27 percent), while smaller percentages represented the biological sciences ( 5 percent), business (10 percent), education ( 7 percent), engineering ( 4 percent), the physical sciences ( 11 percent), professional fields ( 8 percent), the social sciences (14 percent), and other fields (13 percent). This subsample of the FSSE respondents mirrors the characteristics of the overall FSSE sample, which, for many characteristics, is similar to the national sample of faculty (Faculty Survey of Student Engagement, 2009).

Huber and Hutchings's (2005) defining features served as the framework for our dependent measures. The scale measuring institutional encouragement of SoTL (Table 9.1) combines items indicating how much faculty members at a respondent's campus are encouraged to systematically collect information about teaching effectiveness outside of end-ofcourse evaluations, use assessment findings to inform course changes, publicly present information about teaching and learning in their courses, publish on teaching and learning, and collaborate with colleagues on improving teaching and learning. Together these items constitute a reliable scale (alpha $=0.87$ ). The faculty engagement in SoTL scale combines five items focused on how much respondents have incorporated the activities above into their own work (Table 9.1). It too was found to be a reliable scale (alpha $=0.83$ ). Simple frequencies were used to answer our first two questions: (1) to what extent institutions encourage faculty to engage in SoTL and (2) to what extent faculty engage in SoTL. Regression analyses were used to answer the third: what predicts faculty perceptions of institutional encouragement and faculty engagement in SoTL. For the regression models, the dependent variables were standardized prior to the analyses, and the independent variables included individual-level measures similar to those in past studies of faculty teaching-related perceptions and behaviors (Nelson Laird \& Garver, 2010; Umbach \& Wawrzynski, 2005). In addition to characteristics such as gender, race/ethnicity, rank and employment status, course load, and disciplinary area, we added a measure of teaching effort (the average 


\section{Table 9.I SoTL Item Frequencies}

Items

Institutional encouragement of SoTL

Systematically collect information about the effectiveness of their teaching beyond end-of-term course evaluations

Use assessment findings to inform changes made to their courses

Publicly present (for example, lectures or workshops) information about teaching or learning

Publish on teaching and learning

Collaborate with colleagues on improving teaching and learning

Faculty engagement in SoTL

Systematically collect information about the effectiveness of your teaching beyond end-of-term course evaluations

Use assessment findings to inform changes made to your courses Publicly present (for example, lectures or workshops) information about teaching or learning

Publish on teaching and learning Collaborate with colleagues on improving teaching and learning

Note. Some frequency totals do not sum to 100 percent due to rounding.

number of hours in a typical week spent preparing for class per course taught), hypothesizing that engagement in the SoTL would be positively associated with the time one devotes to teaching. Furthermore, in the model predicting faculty engagement in SoTL, we included the standardized measure of faculty members' perceptions of institutional encouragement of SoTL since much of the literature suggests that faculty 
engagement in SoTL (or lack thereof) results from the support (or barriers) in place at institutions (Huber \& Hutchings, 2005). Due to the nested nature of the data (faculty within institutions), which violates the independence assumption of ordinary least-squares analyses resulting in misestimated standard errors, we used STATA release 10 (StataCorp, 2007) to run our regression analyses and produce robust standard errors.

\section{Results}

The frequency distributions contained within Table 9.1 suggest that most faculty members ( 70 percent or more) feel at least "some" encouragement from their institutions for the SoTL activities described by the items. When asked the extent to which their institutions encourage faculty to systematically collect information about the effectiveness of their teaching beyond end-of-term course evaluations, more than seven of ten respondents ( 73 percent) indicated their institutions do this "some," "quite a bit," or "very much." More than four of five ( 82 percent) indicated that their institutions provide at least "some" encouragement for using assessment findings to inform changes made to their courses and for collaborating with colleagues on improving teaching and learning. The smallest percentages of faculty members felt encouraged "quite a bit" or "very much" by their institutions to publicly present information about teaching and learning ( 35 percent) or publish on teaching and learning ( 31 percent). The equivalent percentages for the other items were 42 percent or above.

Table 9.1 also contains the distributions for items about faculty engagement in SoTL. Most faculty (between 84 and 90 percent) indicated that they incorporate systematic collection of information about teaching and learning, use assessment findings for course improvement, and collaborate with colleagues on improving teaching and learning at least "some." These percentages are greater than those for the similar institutional encouragement items, indicating that institutional encouragement may lag faculty engagement in these areas. A different pattern is apparent for the public dissemination items. While more than 70 percent indicated at least "some" encouragement for publicly presenting teaching and learning information and publishing on teaching and learning, 56 percent of respondents indicated "never" publicly presenting, and 44 percent indicated publishing on teaching and learning "some" or more. 
Table 9.2 contains the results of regression analyses. For institutional encouragement of SoTL, the model explained a significant but relatively small amount of variance $\left(F=28.45, p<0.001 ; R^{2}=0.07\right)$. The results suggest that after controlling for other variables in the model, women faculty and instructors on average feel their institution encourages SoTL slightly more-about a tenth of a standard deviation-than their male colleagues $(B=0.08, p<0.05)$. Black or African American faculty members $(B=0.22, p<0.05)$ and Asian/Pacific Islander faculty members $(B=0.36, p<0.001)$ reported significantly higher institutional encouragement when compared to their white peers. Non-U.S. citizens reported greater institutional encouragement $(B=0.18, p<0.01$ ), and those with a doctorate indicated less institutional encouragement than those without a doctorate $(i=-0.15, p<0.001)$.

Course load had a small, positive effect $(B=0.04, p<0.001)$, indicating that, on average and holding constant the other measures in the model, teaching an additional course would correspond to a sense of institutional encouragement for SoTL four one-hundredths of a standard deviation higher. A faculty member's field affected his or her sense of institutional encouragement. Education faculty, on average and after controlling for the other variables in the model, indicated the highest sense of institutional encouragement. Faculty in other fields scored below education faculty by between two-tenths of a standard deviation $(B=-0.19$, $p>0.05$ for professional fields) and over six-tenths of a standard deviation $(B=-0.60, p<0.001$ for social science; $B=-0.63, p<0.001$ for biological science). The number of hours spent in a typical week preparing for each course, our measure of teaching effort, was significant in the institutional encouragement model, but the effect was close to zero. Differences by age, rank, and whether one taught graduate students were small and insignificant.

For faculty engagement in SoTL, the model explained a sizable and significant amount of variance $\left(F=214.68, p<0.001 ; R^{2}=0.39\right.$ ). After controlling for the other factors, women, on average, engaged in SOTL over one-tenth of a standard deviation more than their male peers ( $B=0.12, p<0.001)$. Racial/ethnic differences were evident. Asian/ Pacific Islander faculty $(B=0.15, p<0.05)$ and faculty who preferred not to respond to the race/ethnicity question $(B=0.14, p<0.01)$ reported significantly more engagement than their white counterparts did. Age had a negative effect on engagement. On average and holding the other variables in the model constant, a faculty member ten years older than another would score four one-hundredths of a standard deviation 
Table 9.2 Institutional Encouragement of and Faculty Engagement in SoTL Regression Results

\begin{tabular}{|c|c|c|c|c|c|c|}
\hline & \multicolumn{3}{|c|}{$\begin{array}{c}\text { Institutional } \\
\text { Encouragement of SoTL }\end{array}$} & \multicolumn{3}{|c|}{$\begin{array}{l}\text { Faculty Engagement } \\
\text { in SoTL }\end{array}$} \\
\hline & \multicolumn{3}{|c|}{ Robust } & \multicolumn{3}{|c|}{ Robust } \\
\hline & B & SE & Significance & B & SE & Significance \\
\hline Constant & 0.29 & 0.14 & * & 0.18 & 0.10 & \\
\hline Female & 0.08 & 0.03 & * & 0.12 & 0.04 & *** \\
\hline \multicolumn{7}{|l|}{ Race/ethnicity } \\
\hline White & \multicolumn{3}{|c|}{ reference group } & \multicolumn{3}{|c|}{ reference group } \\
\hline Black/African American & 0.22 & 0.09 & * & -0.00 & 0.04 & \\
\hline Asian/Pacific Islander & 0.36 & 0.08 & $* * *$ & 0.15 & 0.06 & * \\
\hline Hispanic & 0.03 & 0.10 & & 0.10 & 0.08 & \\
\hline Other race/ethnicity & 0.17 & 0.10 & & 0.19 & 0.06 & $* *$ \\
\hline Prefer not to respond & 0.18 & 0.06 & & 0.14 & 0.04 & $* *$ \\
\hline Non-U.S. citizen & 0.18 & 0.06 & ** & 0.00 & 0.07 & \\
\hline Age (in decades) & -0.01 & 0.00 & & -0.04 & 0.00 & $* * *$ \\
\hline Doctorate earned & -0.15 & 0.04 & $* * *$ & 0.04 & 0.04 & \\
\hline \multicolumn{7}{|l|}{ Rank/employment status } \\
\hline Part-time lecturer & \multicolumn{3}{|c|}{ reference group } & \multicolumn{3}{|c|}{ reference group } \\
\hline Full-time lecturer & -0.08 & 0.07 & & 0.04 & 0.06 & \\
\hline Assistant professor & -0.07 & 0.07 & & 0.13 & 0.06 & $*$ \\
\hline Associate professor & -0.12 & 0.07 & & 0.14 & 0.05 & $*$ \\
\hline Full professor & -0.05 & 0.06 & & 0.15 & 0.06 & $*$ \\
\hline Course load & 0.04 & 0.01 & $* * *$ & 0.02 & 0.01 & $* *$ \\
\hline Taught graduate students & 0.00 & 0.05 & & 0.10 & 0.03 & $* *$ \\
\hline \multicolumn{7}{|l|}{ Field } \\
\hline Arts and humanities & -0.50 & 0.07 & *** & -0.43 & 0.05 & $* * *$ \\
\hline Biological science & -0.63 & 0.08 & $* * *$ & -0.51 & 0.08 & $* * *$ \\
\hline Business & -0.41 & 0.09 & $* * *$ & -0.38 & 0.05 & $* * *$ \\
\hline Education & \multicolumn{3}{|c|}{ reference group } & \multicolumn{3}{|c|}{ reference group } \\
\hline Engineering & -0.51 & 0.12 & $* * *$ & -0.41 & 0.08 & *** \\
\hline Physical science & -0.58 & 0.09 & *** & -0.39 & 0.06 & $* * *$ \\
\hline Professional & -0.19 & 0.10 & & -0.28 & 0.05 & $* * *$ \\
\hline Social science & -0.60 & 0.07 & $* * *$ & -0.45 & 0.05 & $* * *$ \\
\hline
\end{tabular}




$\begin{array}{lrrrrrr}\text { Other fields } & -0.45 & 0.09 & * * * & -0.35 & 0.06 & * * * \\ \text { Preparation per course } & 0.02 & 0.01 & * * & 0.02 & 0.00 & * * \\ \text { Institutional } & & & & & & \\ \text { encouragement of SoTL } & - & - & & 0.57 & 0.01 & * * \\ R^{2} & & 0.07 & & 0.39 \\ F & & 28.45^{* * *} & & 214.68^{* * *} \\ \text { Root MSE } & & .97 & & .78\end{array}$

Note. $N=4,229$. Dependent variables standardized prior to running the model. The standardized measure of institutional encouragement of SoTL was used in the faculty engagement model. $B=$ regression coefficient; robust $\mathrm{SE}=$ robust standard error of the regression coefficient; significance: ${ }^{*} p<0.05,{ }^{* *} p<0.01$, $* * * p<0.001$. Constant $=$ the constant term from the regression equation; $F=\mathrm{F}$ statistic for the regression model; root MSE = root mean squared error, which is equivalent to the standard deviation of the error term.

lower than the younger faculty member $(B=-0.04, p<0.001)$. Since our study is not longitudinal, we cannot determine whether this difference is related to getting older (as faculty get older, they decrease their engagement in SoTL), a cohort effect (due to differences in socialization, today's younger faculty tend to do these activities more than today's older faculty), or a change in practice (older faculty did not receive as much training in studying teaching and learning as their younger peers).

All of the position characteristics were significant in the faculty engagement model. Holding all else constant, tenure-track faculty participated in SoTL activities more than their non-tenure-track colleagues did. Assistant $(B=0.13, p<0.05)$, associate $(B=0.14, p<0.05)$, and full $(B=0.15, p<0.05)$ professors participated, on average, over a tenth of a standard deviation above part-time lecturers, while the difference between full-time and part-time lecturers was small and insignificant $(B=0.04, p>0.05)$. Faculty who taught graduate students participated in SoTL activities a tenth of a standard deviation more than those who did not teach graduate students $(B=0.10, p<0.01)$. Field was again a major factor, with education faculty reporting the greater engagement in SoTL activities. Holding the other variables constant, faculty from other fields averaged engagement scores between nearly three-tenths of a standard deviation ( $B=-0.28, p<0.001$ for professional fields) and just over five-tenths of a standard deviation $(B=-0.51, p<0.001$ for biological science) less than their education colleagues, which is not 
surprising since studying teaching and learning is essential to many education faculty members' disciplinary research.

Teaching effort, as measured by average hours per week spent per course taught, had a small but significant effect. For each additional hour of preparation per course, a faculty member would be expected to participate in SoTL activities two-hundredths of a standard deviation more ( $B=0.02, p<0.001)$, holding all else constant. The strongest predictor in the model was institutional encouragement of SoTL. On average and controlling for other factors, faculty members who sensed institutional encouragement one standard deviation more than other faculty would have participated in SoTL activities nearly three-fifths of a standard deviation more than those other faculty $(B=0.57, p<0.001)$.

\section{Discussion and Implications}

The results of this study have implications for faculty and those who support SoTL (for example, academic administrators and faculty development professionals). With a sizable proportion (more than 20 percent) of faculty respondents reporting incorporating the systematic collection of information about teaching effectiveness and using assessment findings to improve their teaching "very much" and most faculty (over 80 percent) doing this type of activity at least "some," our study suggests that SoTL-type activities are part of faculty members' work and, for some, a significant part. This is encouraging for the improvement of teaching and for those who have worked to promote SoTL.

While a similar proportion of faculty report collaborating with colleagues on improving teaching and learning, a potential avenue for going public with one's SoTL work, the proportion of faculty involved in the public presentation and publication of teaching and learning investigations appears to be quite a bit smaller. It is worth noting that having 10 percent of faculty reporting that they have incorporated publishing on teaching and learning into their work "very much" perhaps represents a significant achievement by the SoTL community. However, our results suggest that more work needs to be done to get faculty more involved in going public. To aid in this work, researchers should examine faculty members' awareness of teaching and learning journals and conferences within their fields, as well as their awareness of on-campus opportunities for disseminating research on teaching and learning. Faculty developers can promote awareness among faculty by providing resources and suggesting venues for disseminating research on teaching and learning. 
In addition, there is value in understanding what encourages faculty engagement in SoTL. Our study lends empirical evidence to the claims that institutional support for SoTL is one crucial element (it was the largest predictor in our model of faculty engagement in SoTL). Still, more research is needed to understand what particular practices influence faculty members' sense of support and encouragement and which institutions seem to be effective at encouraging faculty engagement (unfortunately, our sample of institutions was too small to adequately address the question). Furthermore, since our model predicting institutional encouragement of SoTL indicates differences by gender, race, citizenship status, and field, future investigations must examine the various representations and filters of institutional support. Findings from this study suggest that faculty who are often marginalized in higher education (females, Asian/Pacific Islanders) report a higher sense of encouragement to engage in SoTL. What are we to make of this considering the marginalized status of SoTL work at many colleges and universities (Boyer, 1990; Huber \& Hutchings, 2005)? Are institutions actively encouraging marginalized faculty to engage in marginalized research? Or are the mechanisms more indirect? For example, if, as its proponents say, SoTL is an effective educational practice (Huber \& Hutchings, 2005), then the finding that women, faculty of color, and younger faculty incorporate SoTL into their work is consistent with other research showing that these groups engage in effective practices more than their counterparts do (Kuh et al., 2004; Umbach \& Wawrzynski, 2005). What is interesting, however, is that these effects remain significant even after controlling for faculty perceptions of institutional encouragement of SoTL and the other measures in the model. Using gender as an example, our results suggest that a female faculty member is more likely to do SoTL than a male who feels equal levels of support, comes from the same field, and is at the same rank. Faculty developers can use these findings to target populations in promoting scholarly work on teaching and learning.

This same analysis applies to position characteristics. Holding perceptions of institutional support and other characteristics constant, tenuretrack faculty participate in SoTL more than non-tenure-track faculty do. More research is needed to understand why this effect exists. Are nontenure-tack faculty simply less likely to use effective educational practices in general (Umbach, 2007) and therefore SoTL in particular, or are there barriers to engagement in SoTL that could be removed by institutions? Faculty developers seem well positioned to both pursue this line of inquiry and play a role in removing these potential barriers. 
As with other investigations using FSSE (Nelson Laird \& Garver, 2010), our results suggest that academic field is important. Our findings show that faculty and instructors in education perceive greater institutional encouragement of SoTL and, even if perception of institutional encouragement and other factors are held constant, engage in this type of scholarship more than most of their colleagues in other fields. These results could speak to the closer connection between the scholarships of discovery and teaching in education and, possibly, that disciplinary training is important for increasing SoTL work.

\section{Conclusion}

The results of our study suggest that SoTL is embedded in the work of many faculty members and that faculty doing this work do so with at least some sense of support from their institutions. That said, researchers, faculty, and faculty developers have work to do to understand how to encourage SoTL among all faculty, particularly the presentation and publication of investigations into teaching and learning.

Shapiro (2006) and others (Huber \& Hutchings, 2006) argue that a shift is needed in promotion and tenure processes in order to encourage SoTL among faculty. In order for SoTL to be institutionalized in academe, it must be practiced and rewarded (Hatch, 2006; Kreber, 2003). Doing so will ensure that faculty pose and answer questions about teaching and learning, contribute to the profession, and increase the status of teaching in higher education (Trigwell \& Shale, 2004). It will also ensure that educational quality will be in a constant state of improvement, something all faculty and institutions should support.

\section{REFERENCES}

Bender, E. T. (2005, September/October). CASTLs in the air: The SoTL "movement" in mid-flight. Change, 37(5), 40-49.

Boshier, R. (2009). Why is the scholarship of teaching and learning such a hard sell? Higher Education Research and Development, 28(1), 1-15.

Boyer, E. L. (1990). Scholarship reconsidered: Priorities of the professoriate. San Francisco, CA: Jossey-Bass.

Cambridge, B. L. (2000). The scholarship of teaching and learning: A national initiative. In M. Kaplan \& D. Lieberman (Eds.), To improve the academy: Vol. 18. Resources for faculty, instructional, and organizational development (pp. 55-68). San Francisco, CA: Jossey-Bass. 
Chism, N., Sanders, D., \& Zitlow, C. (1987). Observations on a faculty development program based on practice-centered inquiry. Peabody Journal of Education, 64(3), 1-23.

Cottrell, S. A., \& Jones, E. A. (2003). Researching the scholarship of teaching and learning: An analysis of current curriculum practices. Innovative Higher Education, 27(3), 169-181. doi:10.1023/A:1022303210086

Cross, K. P. (1986, September). A proposal to improve teaching or what "taking teaching seriously" should mean. AAHE Bulletin, 39(1), 9-14.

Dobbins, K. (2008). Enhancing the scholarship of teaching and learning: A study of the factors identified as promoting and hindering the scholarly activities of academics in one faculty. International Journal for the Scholarship of Teaching and Learning, 2(2), 1-8.

Faculty Survey of Student Engagement. (2009). FSSE 2009 overview. Bloomington: Indiana University, Center for Postsecondary Research. Hatch, T. (2006). Into the classroom: Developing the scholarship of teaching and learning. San Francisco, CA: Jossey-Bass.

Huber, M. T. (2001, July/August). Balancing acts: Designing careers around the scholarship of teaching. Change, 33(4), 21-29.

Huber, M. T., \& Hutchings, P. (2005). The advancement of learning: Building the teaching commons. San Francisco, CA: Jossey-Bass.

Huber, M. T., \& Hutchings, P. (2006, May/June). Building the teaching commons. Change, 38(3), 24-31.

Hutchings, P., \& Shulman, L. S. (1999, September/October). The scholarship of teaching: New elaborations, new developments. Change, 31(5), 10-15.

Kiener, M. (2009). Applying the scholarship of teaching and learning: Pursuing a deeper understanding of how students learn. InSight: A Journal of Scholarly Teaching, 4, 21-27.

Kreber, C. (2003). The scholarship of teaching: A comparison of conceptions held by experts and regular academic staff. Higher Education, 46(1), 93-121.

Kuh, G. D., Nelson Laird, T. F., \& Umbach, P. D. (2004). Aligning faculty and student behavior: Realizing the promise of greater expectations. Liberal Education, 90(4), 24-31.

McKinney, K. (2004). The scholarship of teaching and learning: Past lessons, current challenges, and future visions. In C. M. Wehlburg \& S. ChadwickBlossey (Eds.), To improve the academy: Vol. 21. Resources for faculty, instructional, and organizational development (pp. 3-19). San Francisco, CA: Jossey-Bass.

McKinney, K. (2007). Enhancing learning through the scholarship of teaching and learning: The challenges and joys of inggling. San Francisco, CA: Jossey-Bass. 
Myers, C. B. (2008). College faculty and the scholarship of teaching: Gender differences across four key activities. Journal of the Scholarship of Teaching and Learning, 8(2), 38-51.

Nelson Laird, T. F., \& Garver, A. K. (2010). The effect of teaching general education courses on deep approaches to learning: How disciplinary context matters. Research in Higher Education, 51(3), 248-265.

Pace, D., \& Erekson, K. A. (2006). The scholarship of teaching and learning history comes of age: A new international organization and Web sitel newsletter. History Teacher, 40(1), 75-78.

Pecorino, P., \& Kincaid, S. (2007). Why should I care about SOTL? The professional responsibilities of post-secondary educators. International Journal for the Scholarship of Teaching and Learning, 1(1), 1-6.

Shapiro, H. N. (2006, March/April). Promotion and tenure and the scholarship of teaching and learning. Change, 38(2), 38-43.

Shulman, L. S. (1999, July/August). Taking learning seriously. Change, 31(4), 10-17.

Shulman, L. S. (2000). From minsk to pinsk: Why a scholarship of teaching and learning? Journal of Scholarship of Teaching and Learning, 1(1), 48-53.

StataCorp. (2007). Stata statistical software: Release 10. College Station, TX: Author.

Trigwell, K., \& Shale, S. (2004). Student learning and the scholarship of university teaching. Studies in Higher Education, 29(4), 523-536.

Umbach, P. D. (2007). How effective are they? Exploring the impact of contingent faculty on undergraduate education. Review of Higher Education, 30(2), 91-123. doi:10.1353/rhe.2006.0080

Umbach, P. D., \& Wawrzynski, M. R. (2005). Faculty do matter: The role of college faculty in student learning and engagement. Research in Higher Education, 46(2), 153-184.

Whitman, P. D., \& Richlin, L. (2007). The status of the scholarship of teaching and learning in the disciplines. International Joumal for the Scholarship of Teaching and Learning, 1(1), 1-17. 